\title{
Benefit of Compressor Washing on Power Output in Oil and Gas Applications
}

\author{
Enyia James Diwa, Dodeye Ina Igbong, Archibong Eso Archibong, Ukpabio Ekpeyong Eyo \\ Department of Mechanical Engineering, Faculty of Engineering, Cross River University of Technology, Calabar, Nigeria \\ Email address: \\ James.enyia@crutech.edu.ng (E. J. Diwa), d.i.igbong@crutech.edu.ng (D. I. Igbong), archibong.eso@crutech.edu.ng (A. E. Archibong), \\ ukpabioeyo@crutech.edu.ng (U. E. Eyo)
}

\section{To cite this article:}

Enyia James Diwa, Dodeye Ina Igbong, Archibong Eso Archibong, Ukpabio Ekpeyong Eyo. Benefit of Compressor Washing on Power Output in Oil and Gas Applications. International Journal of Mechanical Engineering and Applications. Vol. 5, No. 5, 2017, pp. $239-246$. doi: 10.11648/j.ijmea.20170505.11

Received: August 2, 2017; Accepted: August 14, 2017; Published: August 30, 2017

\begin{abstract}
Fouling in gas turbine compressor has proven to be inevitable, but online compressor washing has shown to be promising in mitigating the effects of fouling. Despite the several researches and experiments carried out in laboratories or actual engine operations as presented in literatures, the economic benefit is always very important. This research aim to present the optimum online compressor water washes frequency and determines the creep life of the high pressure turbine HPT, which in this case is the first and second stage of the rotor blades. A Siemens twin shaft industrial gas turbine (SGT200 Tornado) was used for the performance simulation and degradation model. The engine code for Tornado gas turbine was not available in the Turbomatch library, as such data provided by engine manufacturer (Siemens, Lincoln, UK), was applied at the design point and the Turbomatch engine program ran successfully for both design and off-design point with the supplied data. The engine model was deteriorated with knowledge of underlying fouling mechanism and the possibility to apply the design point data using Pythia software and the non-linear gas path analysis with measurable parameters. Larson-Miller parameter LMP approach was applied in determining the effect of increasing turbine entry temperature TET on high power turbine HPT creep life. Hence, the compressor wash optimisation was determined, and the optimum online compressor wash interval was found to be once in every four days. The sensitivity analysis for the price of electricity, shutdown cost, fuel price, and degradation rate was tested, and the results are presented.
\end{abstract}

Keywords: Compressor Washing, Creep, Deterioration, Fouling, Optimisation

\section{Introduction}

Due to its very high reliability and availability over the last fifty years, gas turbines have been the most valuable equipment for electricity production for oil and gas applications [1, 2]. Nowadays, many gas turbine users and operators are mostly concerned with the need to maintain production and reduce operating cost [3]. Monitoring tools are used in order to be able to detect faulty components in the system before failure occur, and thus increase the availability and reliability of the engine. An additional advantage of these tools is the capability of producing early warning before component failure [4], thereby also avoiding costly production outage and replacement parts.

Out of the several methods of gas turbine (GT) diagnostics and degradation prediction available, the linear and non- linear GPA was applied in this research diagnostics simulation, and the technique is based on component map characteristics. The GT will need to operate at high TET in order to produce more power, and in case of extreme fouling of the engine, and then even higher TET will be required to maintain a demand power output. This will lead to increase in engine temperature and HPT blade temperature to be precise. Extreme temperature on the blade results in premature blade creep, clearances are reduced and the possibilities of the blade catching and snapping off are a common occurrence. This is the major reason why it is crucial for blade clearance to be correct, as extreme creep will lead to a destroyed engine.

The mechanism that causes engine degradation includes fouling, erosion, corrosion, and foreign object damage (FOD) [5]. Some of these factors can be minimised and restored by 
compressor washing or cleaning whilst some need repair or replacement of the components.

\section{Causes of Degradation}

The GT ingest large amount of air, tiny particles passes through the filtration system and are adhered on the blade, thereby changing the aerofoil profile, and deteriorate the overall performance of the engine [6]. These result in increased engine temperature and increase in fuel consumption, reduction in power output, and shorter life of the HPT blade. The performance degradation can be divided into:

1. Recoverable losses, which can be recovered from adequate compressor washing

2. Non recoverable losses, which can only be regained by replacement of component parts [7]

\section{Fouling}

Presence of impurities in the ingested combustion air made the compressor blade to become fouled. Using high effectiveness air filters of less than 5 microns is no guarantee that the fine particles will be restricted, as these particles combine with sea salt, water mists, oil vapour etc will deposit and adhere to the compressor blade surface and change the aerofoil shape of the blades, reduce the airflow, increase the temperature and result in over heating of the blades [8]. This leads to the overall plant performance reduction in power output. Fortunately, compressor washing may restore the reduction in performance due to fouling. The performance degradation as a result of compressor fouling which begins as soon as the engine is rotating and is in operation is as shown in figure 1 [9].

\section{Compressor Washing}

Compressor washing is a means of correcting compressor fouling, and the washing can be done either online or offline. The offline or soak is more effective than the online wash, however the unit must be shutdown to cool off. The cooling time depends on the engine involved and varies from very short time periods to many hours. The important thing is that the temperature must be below $100^{\circ} \mathrm{C}$ everywhere inside the engine due to the risk of high stress concentration, the non-duration maybe unacceptable by some users. On the other hand, the online wash is done while the engine is running and does not restore the performance to the original value; therefore, online wash cannot replace offline wash. In recent days, many users are applying both methods which will help to increase the effectiveness of the washing and decrease engine down time due to offline soak wash frequency [10].

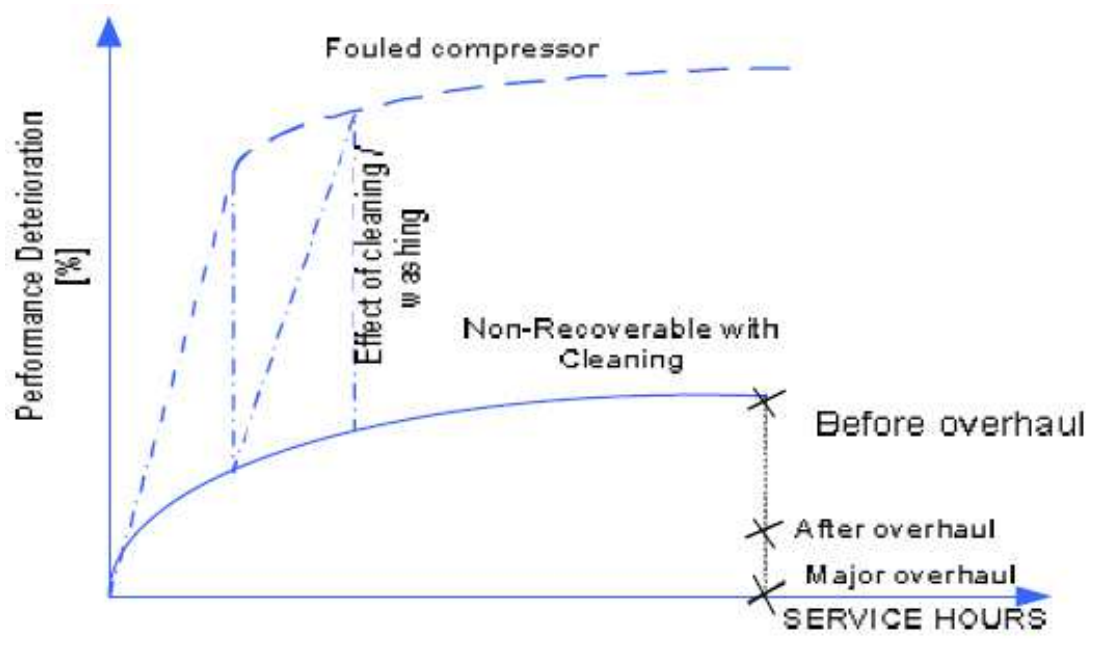

Figure 1. Gas Turbine Compressor Degradation [9].

\section{Methodology}

The Tornado twin shaft IGT is a proven unit for mechanical drive of compressor and pump for the oil and gas industry. The twin shaft is attached together using a flexible coupling for power generation. It ISO base load is $7.680 \mathrm{KW}$, and it design is uniquely simple, employing a single gas generator with twin bearing and two-stage overhung power turbine, rotors are contained in horizontally slip heavy duty casings. It is an ideal unit for industrial electrical generation, particularly in cogeneration or combine heat and power.

The simulation was carried out via Cranfield University
FORTRAN-based program which consist of brick and vector data respectively. The program is able to simulate the design and off-design point and present performance results of the IGT. This code acts as a black box where the results of engine output data power or thrust, fuel consumption, thermal efficiency can be determined by input data at initial stages. It means whatever happens in between two stages can only be calculated individually. Pythia software was also used to simulate the engine performance for both the design and off-design cases. Turbomatch and Pythia are powerful tools for simulation and diagnostics purpose in gas turbine operation, and the results investigated were recorded and 
plotted. The input design point data is as shown in table 1, and the engine model is as presented in figure 2.

Table 1. SGT200 Tornado Engine Design Point.

\begin{tabular}{ll}
\hline Parameters & Values \\
\hline Base load & $7.680 \mathrm{kw}$ \\
Pressure ratio & $12.4: 1$ \\
Inlet mass flow & $29.3 \mathrm{~kg} / \mathrm{s}$ \\
Turbine speed & $10950 \mathrm{rpm}$ \\
Frequency & $50 \mathrm{~Hz}$ \\
Nominal speed & $11085 \mathrm{rpm}$ \\
Inlet ambient temperature & $288 \mathrm{~K}$ \\
Inlet ambient pressure & $101.325 \mathrm{kpa}$ \\
\hline
\end{tabular}

The design point is the particular point in the operating range of a gas turbine when the engine is running at a particular speed, pressure ratio, mass flow at which it was designed for. The design point performance for this particular GT is from Siemens manufacturer, some data are not available for proprietary commercial reasons, the input and output values can be summarised as shown in table 1 .

The engine characteristics under various operating conditions were investigated in the off-design case. This is due to the incessantly changing site ambient conditions such as the quality of air, pressure, humidity, ambient temperature etc. Afterwards, various curves were determined as could be seen in figure 3.

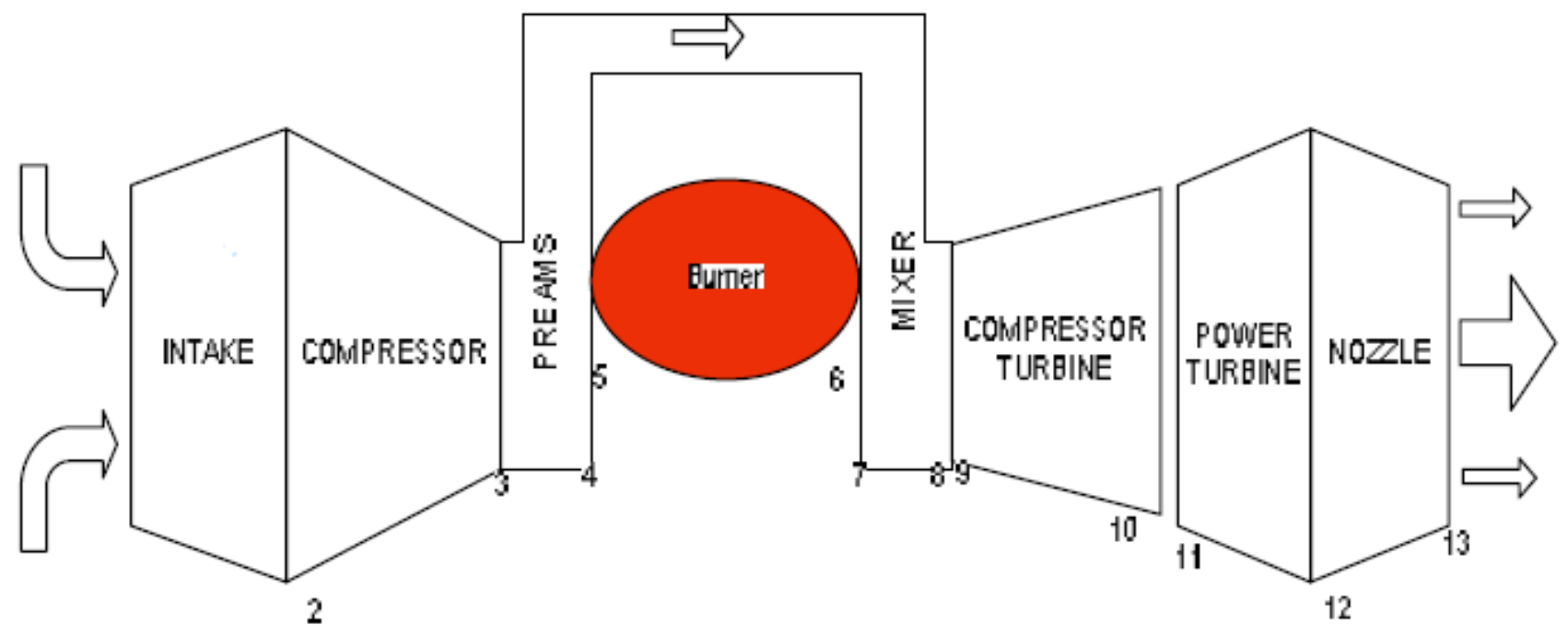

Figure 2. Schematic engine layout for SGT200 Tornado.

The change in ambient temperature and air quality which was simulated by deteriorating the compressor efficiency and NDMF are the major factors considered for the off-design simulation. Other assumptions are as follows:

1. The filtration system is in proper condition and remains constant all through the year.

2. The operating hours for the year is 8000 with availability of approximately $92 \%$.

3. There was 30 hours shutdown for crank washing.

4. Distilled water cost $\$ 0.15$ per liter.

5. Detergent cost about $\$ 300$ / drums [11].

6. The flow rate of the detergent is $1 \mathrm{gal} / \mathrm{min}$ with dilution rate of 1:4.

7. Time for soak and rinse is $30 \mathrm{mins}$ [11].

8. Fuel price is $\$ 0.22 /$ threm and electricity price is \$30/MWhr.

9. Non recoverable degradation rate is $1.5 \%$.

10. Degradation rate from major load is $10 \%$ with interval of 4000 running hours.

\section{Results and Analysis}

Influence of ambient temperature on GT performance.

Gas turbines are very sensitive to the change in inlet temperature. The best engine performance was obtained when the ambient temperature decreases. One would have thought that with the increase in temperatures, thermal efficiency would have decreased. The best engine performance is usually reflected by the higher efficiency and power output. For every $5^{\circ} \mathrm{K}$ change in the ambient temperature, the performance output from Turbomatch is as shown in figure 3.

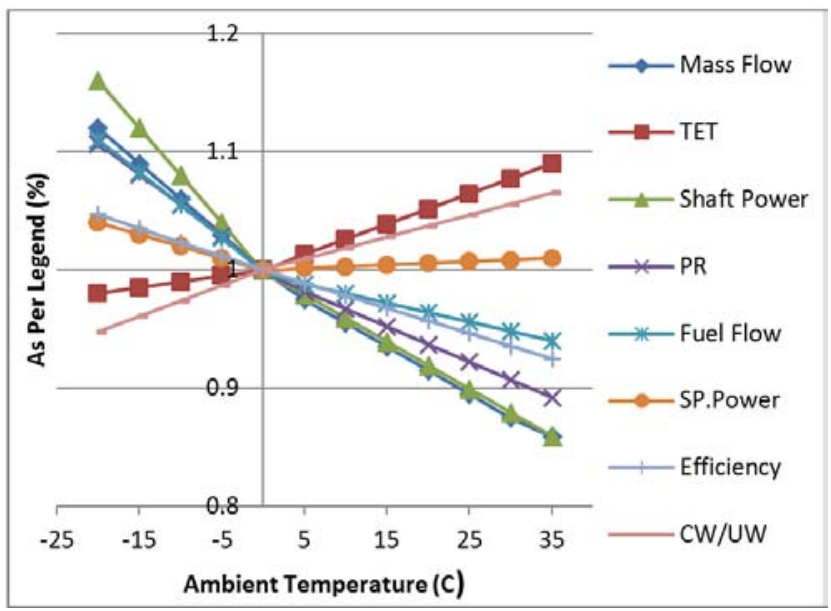

Figure 3. Influence of Ambient Temperature on GT Performance.

The mass flow drops from $1.11 \%$ to about $0.854 \%$, the PR 
falls by about $1.108 \%$ to $0.89 \%$ due to reduced mass flow, the compressor work and useful work ratio increases slightly from $0.947 \%$ to about $1.07 \%$ due to reduced mass flow, the useful work drops from $1.158 \%$ to $0.859 \%$ which will lead to decrease in the thermal efficiency from $1.047 \%$ to $0.924 \%$.

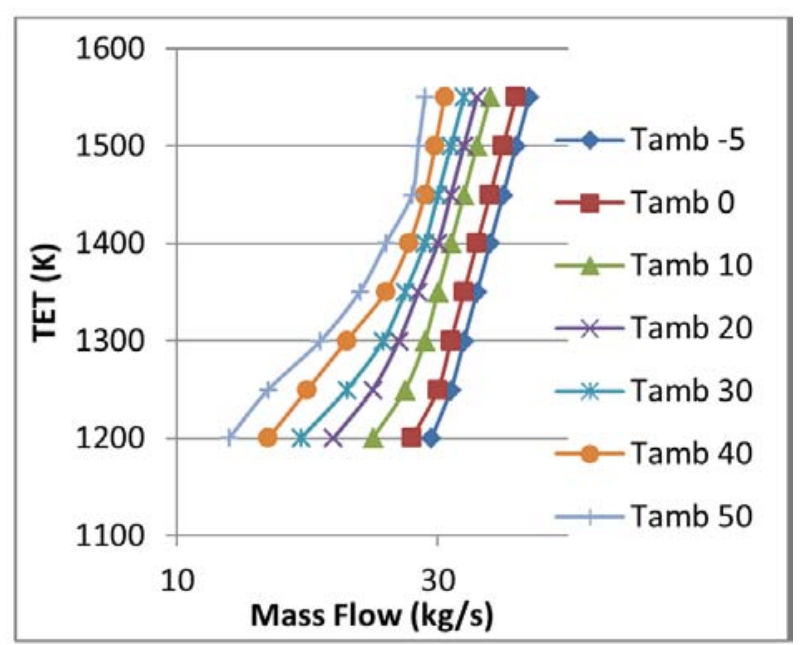

Figure 4. Effect of Ambient Temperature on Mass Flow and TET.

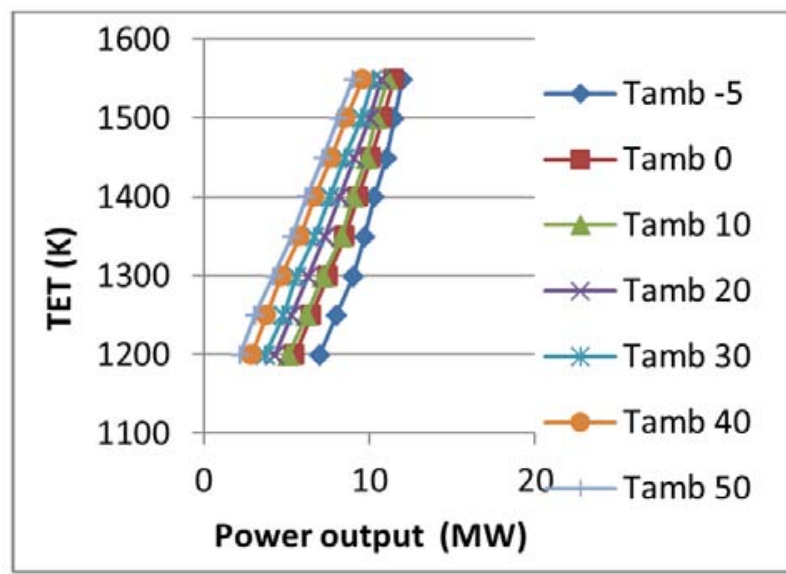

Figure 5. Power output and TET at Varying Ambient Temperature.

The inlet mass flow for the engine increases proportionately with the increase in TET, at different ambient temperatures as can be seen in figure 4 . The two possible ways to balance the effect of change in ambient temperature on GT is either by keeping power constant, or by increasing TET which is accompanied with increase in fuel flow in other to compensate the losses in mass flow. These losses are as a result of reduction in the air density which decreases as the ambient temperature increases.

The compressor requires more power to compress the hot air, the fuel consumption increases and the thermal efficiency drops due to the reduction on power output. This means increase in ambient temperature decreases shaft power, but this can be maintained with increase in TET as shown in figure 5 .

Effect of degradation on engine performance simulation.

GT engines are very sensitive to it component degradation. Compressor fouling appears to be more prone to degradation than other components. The degradation ratio for this compressor fouling is assumed to be $2: 1$ for the efficiency and flow capacity. A $2.5 \%$ drop in isentropic efficiency experiences a $5 \%$ reduction in mass flow, resulting to $1.61 \%$ increase in TET and $5.93 \%$ reduction in power output.

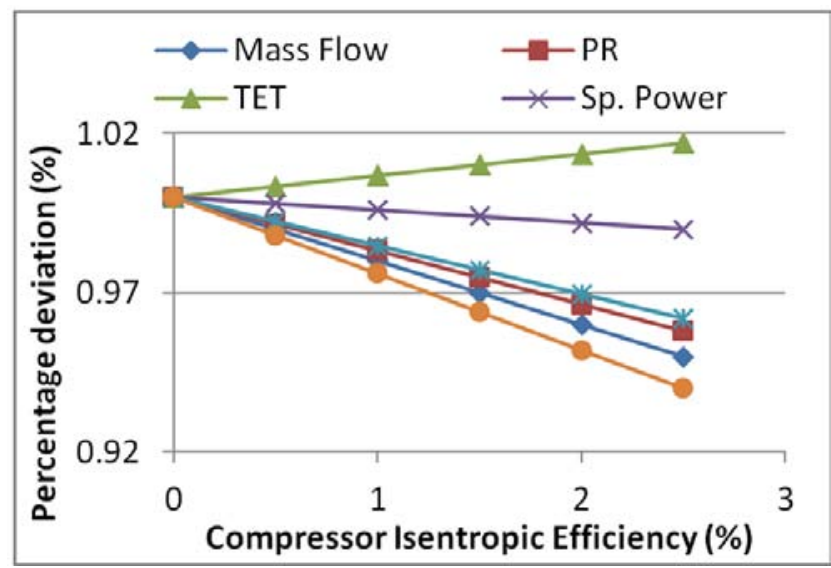

Figure 6. Degradation in engine performance efficiency.

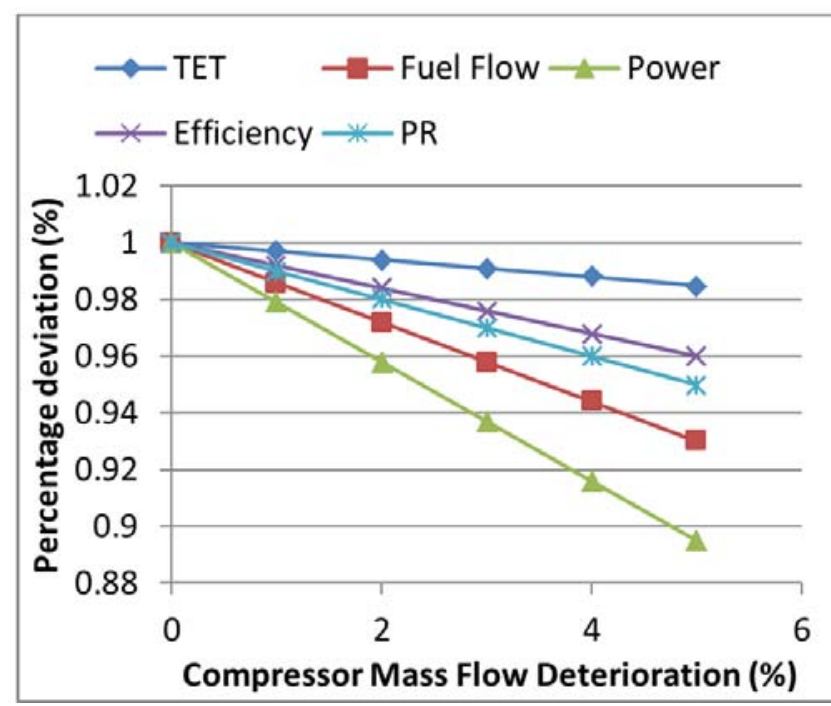

Figure 7. Degradation in engine performance NDMF.

These leads to decrease in other parameters as shown in figure 6 , and a drop in non-dimensional mass flow of $5 \%$ reduces power output by about $10.4 \%$ as shown in figure 7.

\section{Sensitivity Analysis of Measurements Sets}

The sensitivity test was done using linear and non-linear gas path analysis GPA, after the faults have been implanted in the components. Different sets of combination of instruments were made, and the best combination sets is as presented in figure 8. It is observed that T3, T8, and P7 show large effects on the GPA results accuracy. 


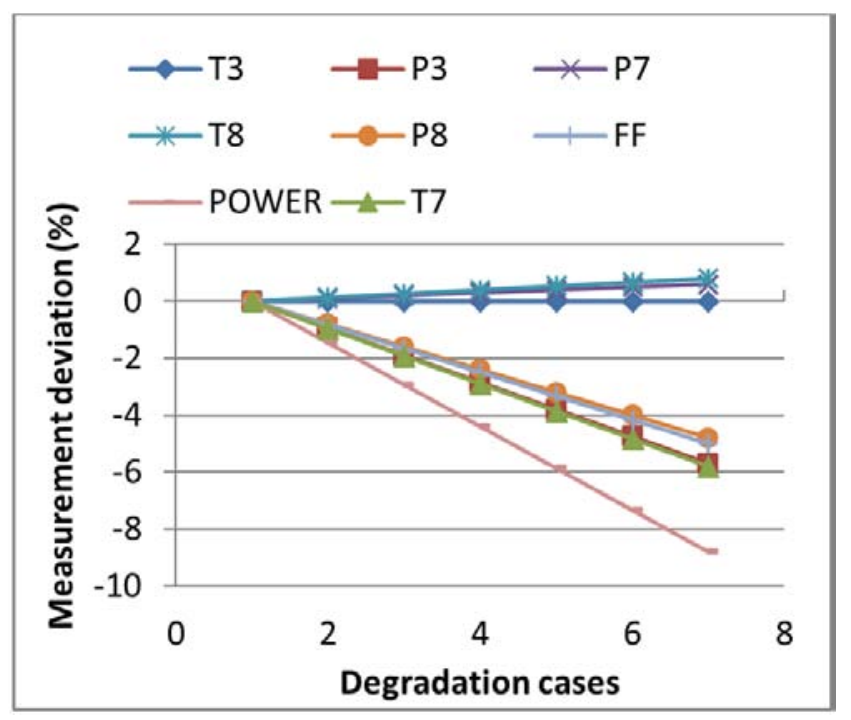

Figure 8. Sensitivity test of measurement sets.

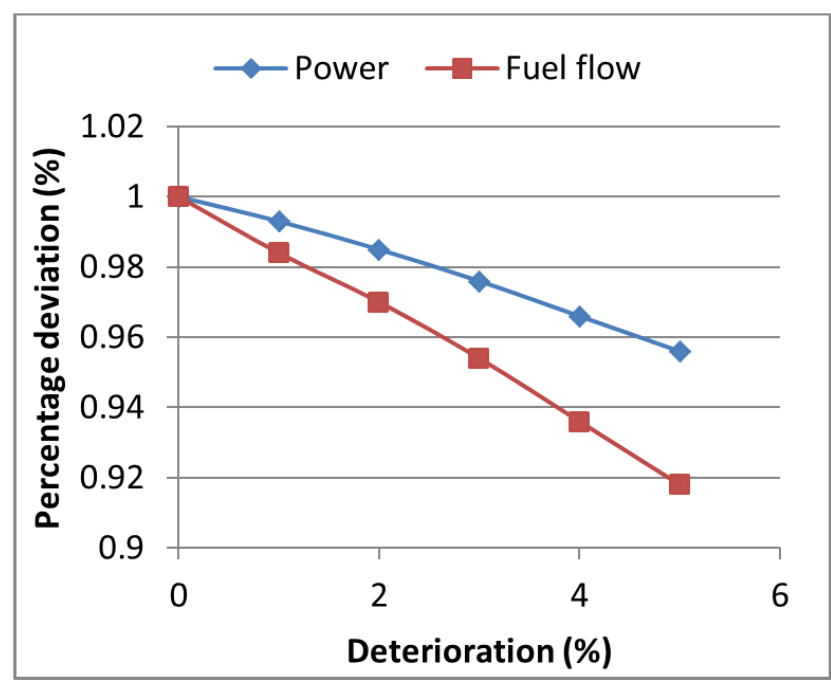

Figure 9. Compressor performance degradation.

The reason for assuming constant shaft speed is to use the output result to find the relationship between the shaft power and fuel consumption when the engine compressor is fouled. It is observed that degrading the compressor by $5 \%$, the output power experiences a loss of $8.3 \%$ with an associated $4.34 \%$ reduction in fuel flow. It shows that the ratio between the power output and fuel flow drop is about $1.87 \%$ as could be seen in figure 9.

\section{Economic Optimisation of Compressor Washing}

It requires high temperatures to maintain required power output for GT, which in turn reduces creep life of the highly stressed hot components [12], thus higher operating costs. Washing the compressor regularly with the use of mobile cleaning rig can reduce accumulated deposits dramatically from the compressor blade, thereby, extending the creep life and reducing cost of operation
[13].

The simple equations below were applied to determine the net profit for a year period of continuous GT operation:

$$
\begin{gathered}
N P=P_{c e}-P_{d e} \\
P_{c e}=P_{p}-F_{c} \\
P_{d e}=P_{c}-F_{n c}+O_{c} \\
O_{c}=C M_{c}+S D_{c} \\
S D_{c}=P_{e} * P_{l} \\
P L_{3}=3 * M L * S D_{t}
\end{gathered}
$$

Some data were obtained from Turbomatch, while some were found from the following literature [10, 14-17].

\subsection{Assumptions}

1 Total running hours for a period of one year is 8640 with approximately $92 \%$ availability.

2 Shutdown time for hand cleaning is 30 hours

3 Natural gas was used

4 Degradation rate from the major load is $10 \%$ with interval of 400 running hours.

5 Inlet filter remains effective all through the year.

6 Non recoverable degradation rate is $1.5 \%$

\subsection{Case Study}

1 Determine the number of cleaning intervals per annum.

2 Profit of degraded engine including loss resulting from cost of production, fuel not consumed, cleaning material and cost of engine shutdown.

3 Profit of clean engine including production and fuel cost.

4 Net profit for both online and offline compressor cleaning.

\subsection{Discussions}

In the following figures $10,12-15$, the $\mathrm{x}$-axis is the number of cleaning intervals per annum, while the y-axis is the cost per hour to compare losses at different intervals for the cost analysis.

There is stability in the clean engine profit while there is no degradation. The optimum offline compressor water wash was found at the seventh cleaning interval, this means the highest net profit and minimum revenue loss, as indicated in figure 10 .

It is also determined as could be seen in figure 11 that the cost of power loss decreases with more compressor washes, slight increase in fuel cost with an increase in the number of cleaning events, shutdown losses cost increase with increase in the number of cleaning events, revenue losses drop up to seven intervals per annum and increase with higher cleaning frequency. 


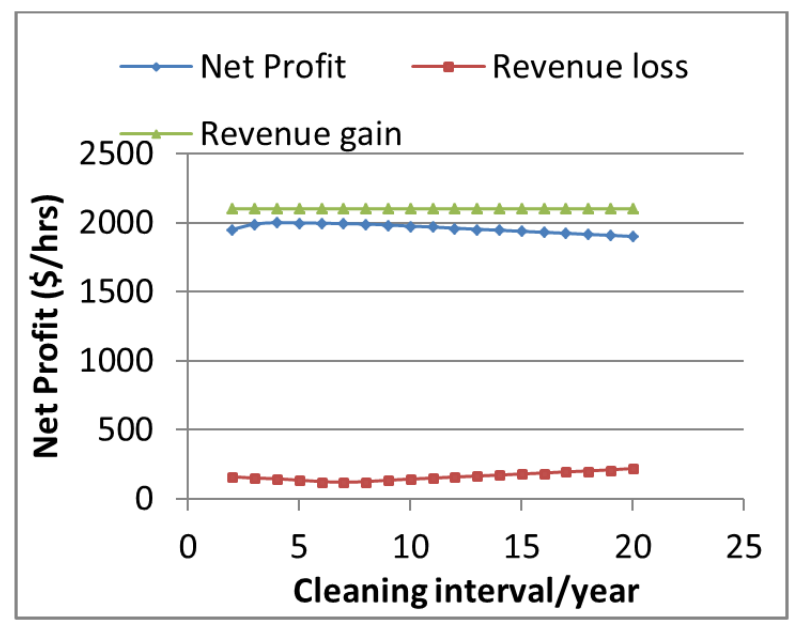

Figure 10. Net Profit for Compressor Cleaning Optimization.

Increase in fuel price indicates decrease in net profit and vice versa, as could be seen in figure 12 . The fuel price was given different values, whilst other variable factors were fixed; it shows that an increase in the number of cleaning intervals will cause reduction in the net profit which is inversely proportional to the change in the price of fuel.

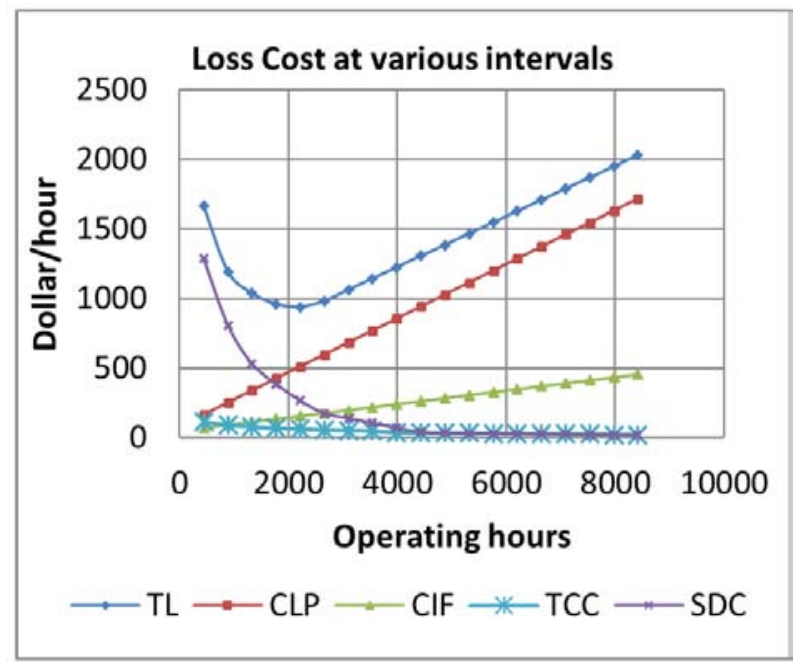

Figure 11. Compressor Cleaning Optimization.

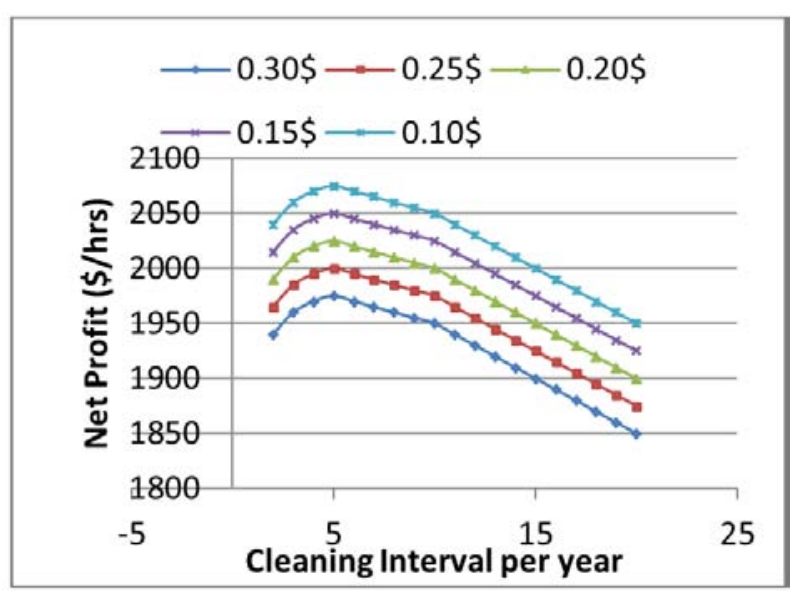

Figure 12. Effects of Change in Fuel Price on Optimum Cleaning Intervals.

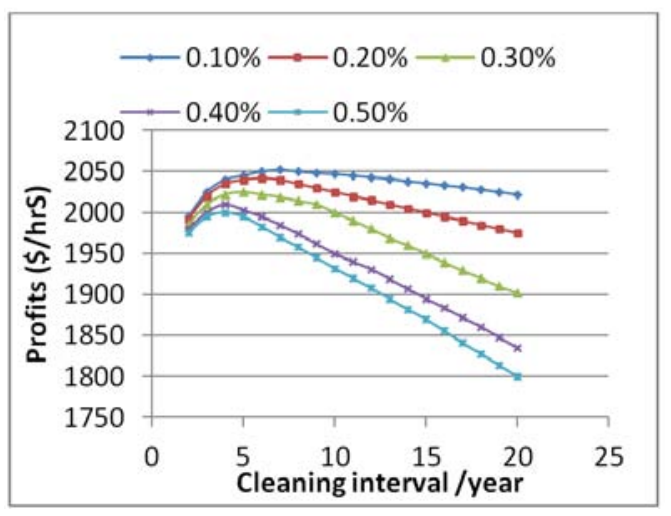

Figure 13. Effects of Degradation rate on Optimum Cleaning Intervals.

The number of cleaning intervals increases with increase in the rate of deposition, which in turn lead to reduction in net profit as could be seen in figure 13. Net profit increases with low rate of deposition. It also increases with the parabolic curve becoming straighter as the deposition is closer to zero value.

A similar procedure to that as shown in figure 13 was applied. The rate of deposition was varied while other factors were fixed. It is observed that the shutdown and cleaning materials cost increases, but the power generated and fuel consumption decreases.

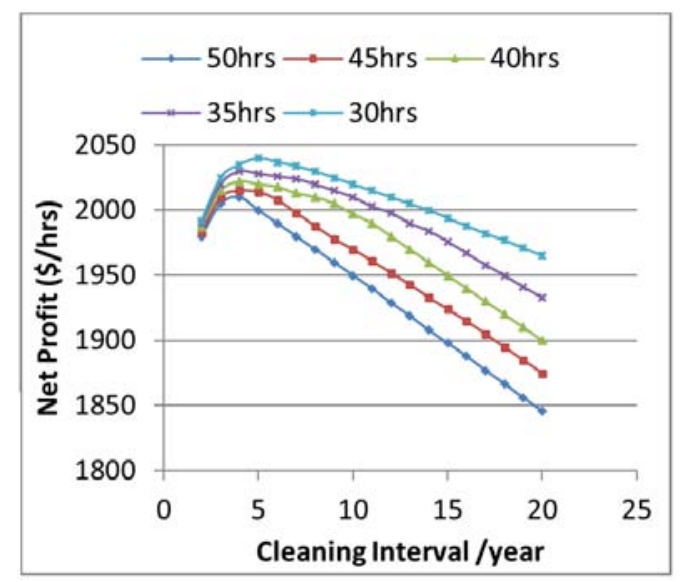

Figure 14. Effect of Shutdown on Cleaning Intervals.

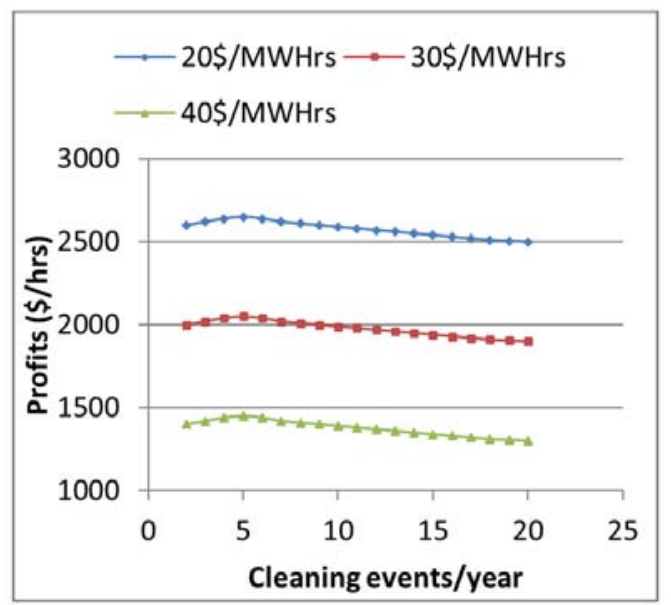

Figure 15. Effects of change in Electricity Price on Optimum Interval. 
Increase in number of engine shutdown hours reduces net profit as can be seen in figure 14. It was observed that the increase in cleaning intervals is inversely proportional to the net profit until the optimum intervals is attained and the net profit will decrease by increase in the number of cleaning intervals. Shutdown hours were varied while other factors were fixed.

The net profit is proportional to the selling price of electricity as shown in figure 15. It is observed that the electricity price increases, which in turn increases the net profit. The increments in the number of intervals will cause the net profit to increase until the optimum cleaning intervals is attained and then start reduce, b using the separate sheet. The electricity price was varied while other variable factors were fixed.

\section{Conclusion}

Compressor washing have been in use for several years now, and its selection offers both technical and economic advantages. The mechanisms for degradation have been discussed in this research to show the variety of possible underlying physical reasons. The design point was first simulated successfully, and the results were very close to the actual engine characteristics, with an error of about $0.01 \%$ using map characteristics with scaling factor supplied from Turbomatch software since the actual map is not published for the sensitivity of commercial reasons.

It was observed that the small engine (SIEMENS SGT200 Tornado) is very sensitive to fouling, as the compressor causes a reduction in mass flow, compressor isentropic efficiency, and power output due to the deposits accumulated on the blades surface. Turbomatch and Pythia software which is Cranfield University in-house software for gas turbine simulation and diagnostics was used to determine the overall performance prediction for the effect of compressor degradation. The linear and non-linearity of the GPA was observed, and the access of the compressor deterioration was also made with eight instrumentation settings which gave very accurate result in case of non-linear GPA. Though will lead to increase in cost, increase in the number of measurement sets will improve the accuracy of the detection of the compressor fouling.

It can be concluded that investigating the optimum off-line compressor wash from the result obtained from the simulation of the compressor degradation, the net profit will be affected by change in the price of electricity, fuel, shutdown and the degradation rate. The analysis confirms that the net profit is very responsive at high numbers of cleaning intervals as a result of increased expenses. The optimum off-line water wash was observed when the net profit at maximum and the revenue losses at minimum at the sixth intervals per year for the degradation limit 7.1 losses in power as shown in optimisation sequences. Therefore the user might save about $£ 258,715$ in case of off-line wash, and $£ 279,451$ in case of on-line wash.

\section{Nomenclature}

Symbols
$\mathrm{CM}_{\mathrm{C}}$
$\mathrm{F}_{\mathrm{c}}$
$\mathrm{NP}$
$\mathrm{O}_{\mathrm{c}}$
$\mathrm{P}$
$\mathrm{p}$
$\mathrm{P}_{\mathrm{ce}}$
$\mathrm{P}_{\mathrm{de}}$
$\mathrm{P}_{\mathrm{L}}$
$\mathrm{P}_{\mathrm{p}}$
$\mathrm{SD}_{\mathrm{c}}$
$\mathrm{T}$
$\mathrm{t}$

Cost of cleaning materials

Fuel cost

Net profit

Other cost

Total Pressure

Static Pressure

Profit from clean engine

Profit from degraded engine

Power losses

Power produce

Cost of engine shutdown

Total Temperature

Static Temperature

$\begin{array}{ll}\text { Abbreviations } & \\ \text { Amb } & \text { Ambient } \\ \text { CIF } & \text { Cost of Increased Fuel } \\ \text { CLG } & \text { Control Logistic Program } \\ \text { CLP } & \text { Cost of Loss Power } \\ \text { DP } & \text { Design Point } \\ \text { FF } & \text { Fuel Flow } \\ \text { GG } & \text { Gas Generator } \\ \text { GPA } & \text { Gas Path Analysis } \\ \text { GT } & \text { Gas Turbine } \\ \text { IGT } & \text { Industrial Gas Turbine } \\ \text { ISO } & \text { International Standard Organisation } \\ \text { LMP } & \text { Larson Miller Parameter } \\ \text { NDMF } & \text { Non-Dimensional Mass Flow } \\ \text { OD } & \text { Off-design Point } \\ \text { PR } & \text { Pressure ratio } \\ \text { PT } & \text { Power Turbine } \\ \text { RMS } & \text { Root Mean Square } \\ \text { SDC } & \text { Shutdown Cost } \\ \text { SGT } & \text { Siemens Gas Turbine } \\ \text { TCC } & \text { Total Cleaning Cost } \\ \text { TET } & \text { Turbine Entry Temperature } \\ \text { TL } & \text { Total Losses }\end{array}$

\section{Acknowledgements}

My sincere appreciation goes to my financial sponsor: Petroleum Technology Development Fund (PTDF), and most especially to God almighty with whom all things are possible.

\section{References}

[1] C. B. Meher-Homji., M. A. Chaker., and H. M. Motiwala, Gas Turbine Performance Deterioration, Proceedings of the $30^{\text {th }}$ Turbomachinery symposium. Texas A 7 M University, Houston, Texas, September 2004. Pp. 139-176, 2001.

[2] R. Syverud., Axial Compressor Performance Deterioration and Recovery through Online Washing, Trondheim: Norwegian University of Science and Technology, 2007. 
[3] A. M. Y. Razak., Industrial Gas Turbines: Performance and Operability. Cambridge: CRC Press, 2007.

[4] P. P. Walsh., and P. Fletcher., Gas Turbine Performance. Oxford: Blackwell Science, 2000.

[5] U. Igie., Degraded Gas Turbine Performance and Economic Analysis: Compressor Fouling and On-line Washing for Industrial Prime Movers, PhD Thesis, Cranfield University, 2012.

[6] R. Kurz., K. Brun., M. Wollie., Deradation Effects on ndustrial Gas Turbines. Journal of Engineering for Gas Turbines and Power, 131 (6), 062410, pp. 1-7, 2009.

[7] P. C. Escher., Pythia: An Object-Oriented Gas Path Analysis Computer Program for General Application, PhD Thesis, Cranfield University, 1995.

[8] I. S. Diakunchak., Performance Deterioration in Industrial Gas Turbines, Journal of Engineering for Gas Turbine and Power, 114(2), pp. 161-168, 1992.

[9] W. S. Walston., K. S. O'Hara., E. W. Ross., T. M. Pollock., and W. H. Murphy, RENE N6: Third Generation Single Crystal Superalloy, GE Aircraft Engines, Cincinnati, OH, 1996.

[10] H. Harada., High Temperature Materials for Gas Turbines: The Present and Future, International Gas Turbine Congress, Tokyo, Japan, November 2-7, Paper No. IGTC2003 Tokyo KS2, 2003 .
[11] A. A. Basendwah., P. Pilidis., Y. I. Li., Turbine offline Water Wash Optimisation Approach for Power Generation. Proceedings of GT2006-90244 ASME Turbo Expo: Power for Land, Sea and Air. Barcelona, Spain, May 8-11, 2006.

[12] A. O. Abu., Integrated Approach for Stress Based Lifing of Gas Turbine Blades. Cranfield University, 2014.

[13] M. F. Abdul Ghafir., I. Y. Li., R. Sing., K. Huang., X. Feng., Impact of Operation and Health Conditions on Gas TURBINE Hot Section Creep Life Factor Approach. ASME, Turbo Expo, Glasgow; June 14-18, 2010.

[14] J. Kristin., A. Mohsen., G. Magnus., Variation in Gas Turbine Blade Life and Cost due to Compressor Fouling. A Thermoeconomic Approach. International Journal of Applied Thermodynamics, vol. 5, no. 1, pp. 37-47, 2002.

[15] H. Khatib., Economic Evaluation of Projects in the Electricity Supply Energy Market. Hawaii International Conference, System Sciences, Proceedings of the $34^{\text {th }}$ Annual Conference, 3-6 January, 2001.

[16] R. Panneerselvam., Engineering Economics. $2^{\text {nd }}$ Edition, October 2013.

[17] J. D. Enyia, Y. Li., D. I. Igbong, I. Thank-God. Industrial Gas Turbine On-line Compressor Washing for Power Generation. International Journal of Engineering Research and Technology, ISSN: 2278-0181, vol. 4 Issue 08, August 2015. 